Résumés des conférences et travaux

\title{
Guy Beaujouan (1925-2007)
}

Danielle Jacquart

\section{(2) OpenEdition \\ Journals}

Édition électronique

URL : https://journals.openedition.org/ashp/601

DOI : 10.4000/ashp.601

ISSN : 1969-6310

Éditeur

Publications de l'École Pratique des Hautes Études

\section{Édition imprimée}

Date de publication : 1 octobre 2009

Pagination : xvii-xx

ISSN : 0766-0677

Référence électronique

Danielle Jacquart, "Guy Beaujouan (1925-2007) », Annuaire de l'École pratique des hautes études

(EPHE), Section des sciences historiques et philologiques [En ligne], 140 | 2009, mis en ligne le 23 octobre 2009, consulté le 06 juillet 2021. URL : http://journals.openedition.org/ashp/601 ; DOI : https:// doi.org/10.4000/ashp.601

Ce document a été généré automatiquement le 6 juillet 2021.

Tous droits réservés : EPHE 


\section{Guy Beaujouan (1925-2007)}

\section{Danielle Jacquart}

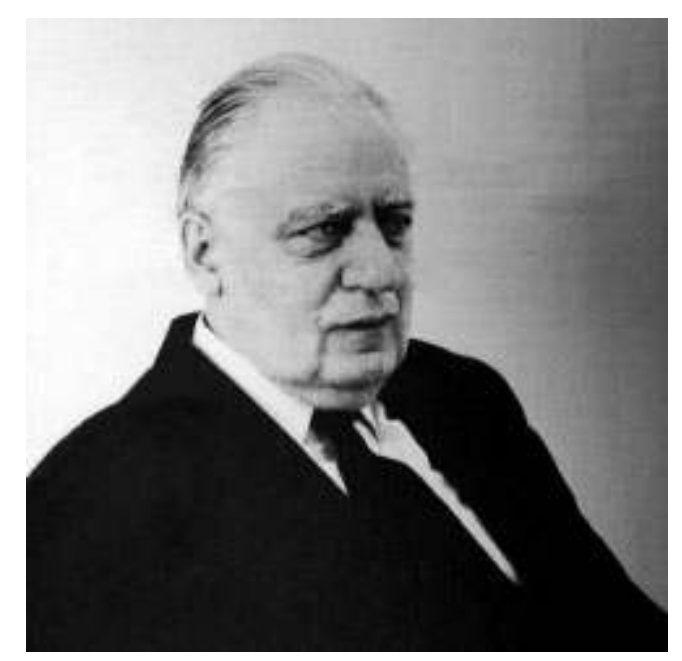

Cliché : Pierre Granier

1 GUY BEAUJOUAN est mort subitement, le 5 octobre 2007, à son domicile parisien. Pendant les deux années précédentes, il avait souffert de sévères alertes cardiaques. Très attaché à l'École pratique des hautes études, et en particulier à la Section des sciences historiques et philologiques, il avait néanmoins mis un terme à son enseignement dès son départ à la retraite, en 1993, malgré les encouragements à continuer que lui manifestaient ses auditeurs. Il n'assistait à la conférence de son successeur que sur invitation exprès, ne souhaitant pas, disait-il avec la délicatesse qui le caractérisait, jouer à la statue du commandeur. Cela ne l'empêchait pas de s'intéresser à ce qui s'y passait et de recevoir chez lui des jeunes chercheurs pour leur prodiguer des conseils ou leur prêter des livres. Il avait aussi cessé, peu de temps après son départ à la retraite, d'assister aux assemblées de la Section: la disparition de collègues amis l'attristait, l'évolution de l'École le déconcertait. Cette prise de distance n'était pas le signe d'une indifférence, bien au contraire, et la croix de chevalier de la Légion d'honneur, qu'il reçut en 2003 lui procura un réel plaisir, car elle témoignait d'une reconnaissance des services qu'il avait rendus à l'institution. Par sa conférence du mercredi soir, que ne 
manquaient pas de suivre les spécialistes étrangers de passage, et par sa réputation internationale, il avait contribué à la renommée de la Section. Bien des thèses de doctorat d'État ou nouveau régime se sont élaborées sous sa direction effective, dans les années où les directeurs d'études n'étaient pas habilités à remplir officiellement cette fonction au sein de l'École.

2 Né le 23 juin 1925 à Orléans, Guy Beaujouan fit ses études secondaires à Angers, où son père exerçait de hautes fonctions dans l'administration des postes. Ce fut avec l'aide de ses professeurs du lycée David d'Angers qu'il prépara son entrée à l'École des chartes. Dans cette vénérable institution, il fit preuve d'originale innovation en soutenant, en 1947, une thèse sur l'arithmétique médiévale, qui lui valut le prix Auguste Molinier. À cette époque, les chartistes n'avaient pas encore le statut d'élèves-fonctionnaires stagiaires et n'étaient donc pas assurés de trouver un poste, une fois obtenu leur diplôme d'archiviste-paléographe. Pour Guy Beaujouan, la situation se compliqua en raison de la déficience visuelle, inscrite sur son visage, qu'il avait depuis la naissance, mais que de délicates interventions chirurgicales durant son enfance avaient réussi à pallier. Alors que sa thèse de l'École des chartes avait montré qu'il pouvait déchiffrer les manuscrits médiévaux les plus difficiles, l'administration des bibliothèques le jugea inapte à entrer dans la carrière qu'il avait choisie. Il parlait peu de cette déception, qu'il ressentit comme une blessure profonde et qui lui donna la hantise des visites médicales. Il se contentait d'ironiser sur son passage dans une banque, où il étonnait ses collègues en faisant les opérations de calcul à la mode médiévale avec une extrême rapidité. Ce fut grâce au soutien de Charles Samaran qu'il entra, après cette expérience bancaire, à la Section contemporaine des Archives nationales. Le séjour qu'il fit à la Casa de Velàzquez, de 1950 à 1952, donna un nouveau tournant à ses recherches, jusque là centrées sur l'histoire de l'arithmétique. Non seulement il entreprit le recensement des manuscrits scientifiques conservés dans les bibliothèques espagnoles, qu'il mit à profit au fil des années dans la publication d'utiles instruments de travail, mais il s'ouvrit à l'histoire de la science dans la péninsule Ibérique, notamment à l'aube des Grandes Découvertes, un domaine de recherche que les interférences idéologiques contribuaient à brouiller et où il put exercer toute sa rigueur et son esprit critique. La rencontre, à Madrid, de celle qui devint son épouse, une Castillane, renforça ses liens avec l'Espagne. À son retour de la Casa de Velàzquez, Guy Beaujouan réintégra les Archives nationales, cette fois à la Section moderne, où il fut chargé des documents pouvant intéresser l'histoire des sciences; son implication dans cette tâche ne s'interrompit pas à son départ des Archives nationales, et il fut pour beaucoup, plusieurs années plus tard, dans la création d'un centre spécialisé à la Cité des sciences de La Villette, dirigé par un conservateur d'archives en détachement. Dès la fin des années 1950, Guy Beaujouan s'était fait un nom en histoire des sciences, en France comme à l'étranger, prenant des responsabilités dans les institutions représentatives de la discipline, écrivant des synthèses sur la période médiévale. En 1957 paraissait un long chapitre dans l'Histoire générale des sciences dirigée par René Taton. Depuis lors, il ne cessa de livrer périodiquement l'état de ses réflexions en collaborant à des ouvrages collectifs pour un public plus vaste que celui des spécialistes, que ces ouvrages fussent consacrés à la période médiévale dans son ensemble ou à l'histoire des sciences à travers les siècles. Par sa participation à de tels projets, il entendait promouvoir l'étude des savoirs scientifiques du Moyen Âge, tant auprès des historiens médiévistes que des historiens des sciences, les uns et les autres étant souvent portés à réduire ce domaine 
à une curiosité marginale. Lui-même se considérait à la fois comme un historien médiéviste et comme un historien des sciences.

Dès 1956, il avait pu dispenser un enseignement à la IV Section, dans le cadre d'une charge de conférence. Après trois années passées au CNRS qui lui avaient fait quitter définitivement le métier d'archiviste, une direction d'études lui était confiée en 1963 avec un intitulé alors inédit « Histoire des sciences au Moyen Âge ». L'année précédente était paru, dans la Bibliothèque de l'École des hautes études hispaniques, son ouvrage sur les manuscrits scientifiques médiévaux de l'université de Salamanque et de ses "Colegios Mayores », qui lui avait valu, en 1960, le titre d'élève diplômé de la Section des sciences historiques et philologiques. À la liste de ses publications donnée en 1994 dans les mélanges qui lui furent offerts, quelques titres doivent être ajoutés, en particulier une mise au point sur les rapports entre théorie et pratique, publiée à Rome en 2003 dans la Storia della Scienza, à laquelle il avait porté le plus grand soin et à laquelle il tenait beaucoup. En effet, si les deux thèmes principaux de ses travaux furent l'histoire de l'arithmétique et la science en Espagne, thèmes autour desquels fut réunie une série d'articles dans deux recueils de Variorum, l'articulation entre les savoirs théoriques et leur mise en œuvre pratique, difficilement décelable pour la période médiévale, constitua l'un de ses sujets privilégiés de réflexion. Il s'intéressait plus volontiers aux aspects concrets de l'activité scientifique qu'aux méandres d'une pensée toute teintée de raisonnement scolastique. Il affectait de dire qu'il se méfiait des philosophes, qu'ils fussent médiévaux ou contemporains, même s'il comptait beaucoup d'amis parmi ces derniers. C'était en un style sobre, parfois incisif, toujours efficace, qu'il présentait, sans inutile prolixité, les résultats de ses recherches, jugeant que seules méritaient d'être publiées des informations inédites ou des interprétations entièrement nouvelles.

Son œuvre pionnière a ouvert maintes voies et nombre de manuscrits conservés en Espagne, qu'il a sortis de l'oubli, restent encore à exploiter. Tous ceux qui l'ont côtoyé ont pu apprécier sa riche personnalité, mêlée de fierté et de générosité. Le souvenir en est heureusement gardé grâce à l'entretien qu'il avait accordé à Jean-Patrice Boudet, à Joël Chandelier et à Nicolas Weill-Parot et qui a été publié dans la revue Médiévales en 2004. En répondant, avec le franc-parler qu'il affectionnait, aux questions d'interlocuteurs, tous trois engagés dans une recherche en histoire des sciences au Moyen Âge, à des stades différents de leur carrière depuis le doctorant de l'École pratique des hautes études jusqu'au professeur des universités, Guy Beaujouan montrait une nouvelle fois son attachement à transmettre son savoir et son expérience humaine, une tâche qu'il avait accomplie avec conscience et conviction à la Section des sciences historiques et philologiques pendant trente ans.

\section{INDEX}

Thèmes : Nécrologies 